\title{
Cardiac function and haemodynamics in alcoholic cirrhosis and effects of the transjugular intrahepatic portosystemic stent shunt
}

\author{
M Huonker, Y O Schumacher, A Ochs, S Sorichter, J Keul, M Rössle
}

\begin{abstract}
Background-A portosystemic stent shunt may impair cardiac function and haemodynamics.

Aims-To investigate the effects of a transjugular intrahepatic portosystemic shunt (TIPS) on cardiac function and pulmonary and systemic circulation in patients with alcoholic cirrhosis.

Patients/Methods-17 patients with alcoholic cirrhosis and recent variceal bleeding were evaluated by echocardiography and catheterisation of the splanchnic and pulmonary circulation before and after TIPS. The period of catheter measurement was extended to nine hours in nine of the patients. The portal vein was investigated by Doppler ultrasound before and nine hours after TIPS.
\end{abstract}

Results-Baseline echocardiography showed the left atrial diameter to be slightly increased and the left ventricular volume to be in the upper normal range. Nine hours after TIPS, the left atrial diameter and left ventricular end diastolic volume were increased (by $6 \%(p<0.01)$ and $7 \%(p<0.01)$ respectively $)$; end systolic volume had not changed significantly. Invasive measurements showed a sharp increase in right atrial pressure (by $101 \%$; $\mathbf{p}<0.01$ ), mean pulmonary artery pressure (by $92 \%$; $<0.01$ ), pulmonary capillary wedge pressure (by $111 \%$; $<0.01$ ), and cardiac output (8.1 (1.6) to 11.9 (2.4) $1 / \mathrm{min} ; \mathrm{p}<0.01)$. Systemic vascular resistance decreased (824 (242) to 600 (265) dyn $\left.\cdot s \cdot \mathrm{cm}^{-5} \mathrm{p}<0.01\right)$, and total pulmonary resistance increased $(140 \quad(58.5)$ to 188 (69.5) $\left.\mathrm{dyn} \cdot \mathrm{s} \cdot \mathrm{cm}^{-5} ; \mathrm{p}<0.05\right)$. Total pulmonary resistance $(12 \%$; NS), cardiac output $(1.4 \mathrm{l} / \mathrm{min} ; \mathrm{p}<0.05)$, and portal vein blood flow $(1.41 / \mathrm{min} ; \mathrm{p}<0.05)$ remained elevated for nine hours after TIPS in the subgroup. Portoatrial pressure gradient $(43 \%$; $\mathbf{p}<0.05)$, portohepatic vascular resistance $(72 \% ; \mathbf{p}<0.05)$, and systemic vascular resistance $(27 \% ; p<0.01)$ were consistently reduced.

Conclusions-The increase in the left atrial diameter, the pulmonary capillary wedge pressure, and total pulmonary resistance observed after the TIPS procedure reflected diastolic dysfunction of the hyperdynamic left ventricle in patients with alcoholic cirrhosis. The haemodynamic effects of the portosystemic stent shunt itself on the splanchnic circulation seem to be mainly responsible for the further decrease in systemic vascular resistance. TIPS may unmask a coexisting preclinical cardiomyopathy in patients with alcoholic cirrhosis and portal hypertension.

(Gut 1999;44:743-748)

Keywords: alcoholic cirrhosis; portosystemic stent shunt; cirrhotic cardiomyopathy; ventricular function; pulmonary circulation; systemic circulation

It has been known for more than four decades that hepatic cirrhosis is associated with cardiovascular abnormalities. The initial studies performed in the early 1950s documented the existence of a hyperdynamic circulation in cirrhosis, manifested by increased cardiac output and reduced systemic vascular resistance. ${ }^{1}$ Overt heart failure is generally not a prominent feature of hepatic cirrhosis, because the marked peripheral vasodilation reduces the afterload of the left ventricle, thus unloading the heart and masking any severe manifestation of heart failure. ${ }^{2-4}$ However, when cirrhotic patients are challenged by pharmacological or physiological stress, a syndrome termed "cirrhotic cardiomyopathy" may become apparent. ${ }^{56}$

The transjugular intrahepatic portosystemic stent shunt (TIPS) is a decompressive treatment for portal hypertension. It is based on the creation of a intrahepatic channel between the portal vein and the right hepatic vein. ${ }^{78}$ The sudden decompression of the splanchnic circulation induces a blood volume shift into the systemic vascular bed, which may be comparable with that observed during surgical shunt procedures. ${ }^{9} 10$ This may explain the occasional clinical observation of acute heart failure after TIPS or a surgical portocaval shunt. ${ }^{11-13}$

The purpose of this study was to determine the acute and delayed effects of a portosystemic stent shunt on cardiac dimensions and function as well as on pulmonary and systemic circulation in patients with alcoholic cirrhosis treated for variceal bleeding by TIPS.

\section{Methods}

PATIENTS

We selected 17 consecutive patients (14 men and three women, mean (SD) age 50.6 (9.9) years) with alcoholic cirrhosis and recent variceal bleeding, who had been in a stable circulatory state for at least two weeks before

Abbreviation used in this paper: TIPS, transjugular intrahepatic portosystemic stent shunt. 
Table 1 Dimensions and function of the left heart in 17 patients before and nine hours after insertion of a transjugular intrahepatic portosystemic stent shunt (TIPS)

\begin{tabular}{lllll}
\hline Variables measured & Normal range & Before TIPS & Nine hours after TIPS & Significance \\
\hline HR (beats/min) & $70(8)$ & $80.1(14.6)$ & $82.2(16.1)$ & $\mathrm{NS}$ \\
LA $(\mathrm{mm})$ & $33(4.7)$ & $41.7(4.6)$ & $44.3(4.4)$ & $\mathrm{p}<0.01$ \\
LVEDV $(\mathrm{ml})$ & $127(18)$ & $153.7(29.7)$ & $164.6(31.9)$ & $\mathrm{p}<0.01$ \\
LVESV $(\mathrm{ml})$ & $50(10)$ & $54.1(17.2)$ & $52.9(16.5)$ & $\mathrm{NS}$ \\
$\mathrm{CO}_{\mathrm{E}}(1 / \mathrm{min})$ & $5.4(1)$ & $7.89(1.70)$ & $9.14(2.21)$ & $\mathrm{p}<0.01$ \\
SV $(\mathrm{ml})$ & $76(13)$ & $99.6(20.7)$ & $111.7(21.7)$ & $\mathrm{p}<0.01$ \\
LVEF $(\%)$ & $59(6)$ & $65.2(8.1)$ & $68.3(7.9)$ & $\mathrm{p}<0.01$ \\
\hline
\end{tabular}

Values are expressed as mean (SD).

HR, heart rate; LA, left atrial diameter; LVEDV, end diastolic left ventricular volume; LVESV, end systolic left ventricular volume; $\mathrm{CO}_{\mathrm{E}}$, cardiac output; $\mathrm{SV}_{\mathrm{E}}$, stroke volume; $\mathrm{LVEF}$, left ventricular ejection fraction. output $\left(\mathrm{CO}_{\mathrm{E}}\right)$ of the left ventricle were calculated using the following formulae:

$$
\begin{aligned}
& \mathrm{SV}_{\mathrm{E}}=\mathrm{LVEDV}-\mathrm{LVESV} \\
& \mathrm{LVEF}=\mathrm{SV}_{\mathrm{E}} / \mathrm{LVEDV} \times 100 \\
& \mathrm{CO}_{\mathrm{E}}=\mathrm{SV}_{\mathrm{E}} \times \mathrm{HR}
\end{aligned}
$$

All values reported were calculated from three consecutive cardiac cycles.

CATHETER MEASUREMENT

Before TIPS implantation, a Swan-Ganz flow directed monitoring catheter (model 93A-131, size 7F; American Edwards Laboratories, Santa Ana, California, USA) was introduced via the cubital vein and placed in the pulmonary artery. The right atrial pressure, the systolic, diastolic and mean pulmonary artery pressures, as well as the pulmonary capillary wedge pressure were measured (Servomed SMV $104 \mathrm{~T}$; PPC Hellige, Freiburg, Germany). Cardiac output was determined using the thermodilution technique (Edwards Laboratories, model 9520A), and blood pressure was measured with a mercury sphygmomanometer. The portosystemic shunt was created using a balloon-expandable Palmaz stent with a lumen diameter of $8-12 \mathrm{~mm}^{7}$ All measurements were repeated immediately after this procedure. In a subgroup of nine randomly selected male patients (mean age 47.9 (10.6) years, Child-Pugh grade A $(\mathrm{n}=4)$, Child-Pugh grade $B(n=4)$, Child-Pugh grade $C(n=1))$, further follow up measurements were performed at 90 minutes, three, six, and nine hours after TIPS. The portoatrial pressure gradient was determined before opening of the shunt, and 5 to 10 minutes as well as nine hours after shunt procedure with the pressure device used for the measurements in the pulmonary circulation. All values were derived in triplicate by the same investigator. Cardiac output, systemic vascular resistance, and total pulmonary resistance were calculated as described. ${ }^{17}$

\section{DUPLEX SONOGRAPHY}

In the subgroup (nine patients), portal vein blood flow velocity was measured by duplex sonography (Ultramark 9; ATL, Bothell, Washington, USA). The portal vein diameter (d) was determined by real time sonography before and nine hours after the TIPS implantation. The measurements were performed in triplicate. Portal vein blood flow $(F)$ was estimated from the equation $F=\pi d^{2} V_{\max }(1 / 8)$. Portohepatic vascular resistance was calculated as the difference in portoatrial pressure gradient divided by the portal vein blood flow.

\section{STATISTICAL ANALYSIS}

Statistical analysis was performed using the Statistical Package for Social Sciences (SPSS for Windows, 7.5). All data were tested for normal distribution. These were then expressed as mean (SD). The Wilcoxon test for paired data was used. The influence of the TIPS procedure was tested by analysis of variance and covariance. This was performed in conjunction with repeated measures and pairwise multiple comparison (StudentNewmann-Keuls method). Differences with a 


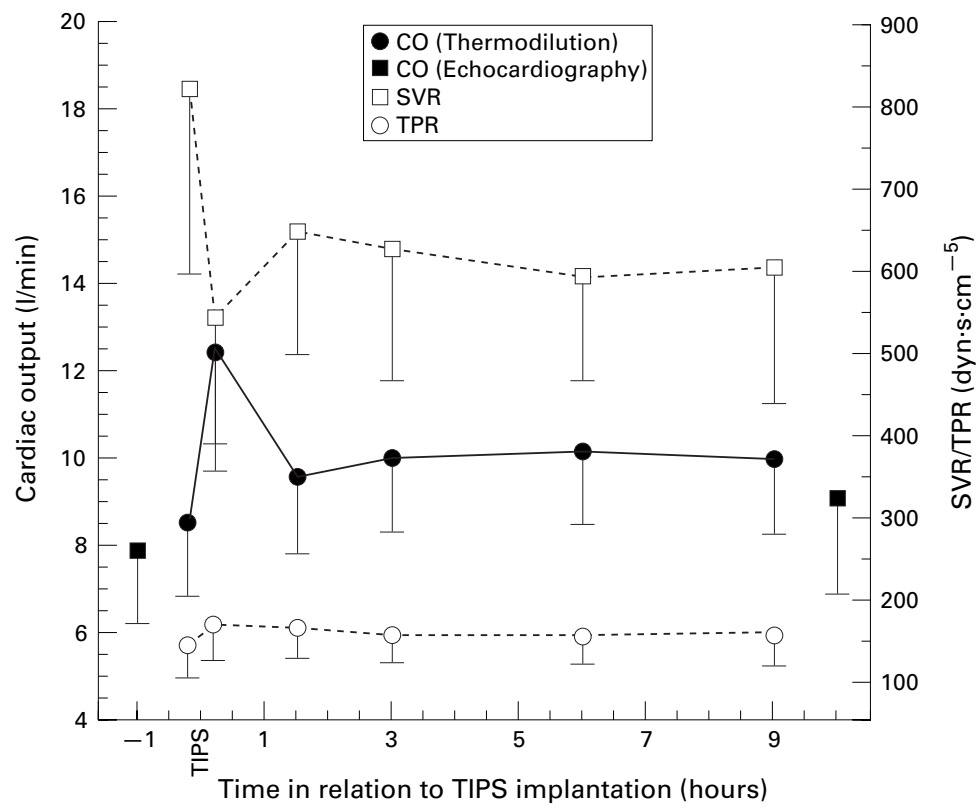

Figure 1 Time course of cardiac output (CO), systemic vascular resistance (SVR), and total pulmonary resistance (TPR) before and within nine hours of a transjugular intrahepatic portosystemic stent shunt (TIPS) in nine patients with portal hypertension. Values are expressed as mean (SD).

statistical error probability of $<5 \%$ were considered significant.

\section{Results}

Table 1 summarises the results of the echocardiographic examination before and nine hours after the stent implantation. Before TIPS, left atrial diameter, left ventricular end diastolic volume, stroke volume, and cardiac output were distinctly above the upper normal limit. Left ventricular end systolic volume and left ventricular ejection fraction were within the upper limit of the normal range. Nine hours after the TIPS procedure a significant increase in left atrial diameter $(2.5(1.5) \mathrm{mm} ; 6 \%)$, left ventricular end diastolic volume (11.0 (13.1) $\mathrm{ml} ; 7 \%)$, stroke volume (12.2 (12.1) $\mathrm{ml} ; 12 \%)$, cardiac output (1.27 (1.13) $1 / \mathrm{min} ; 16 \%)$, and left ventricular ejection fraction $(3.2(2.6) \%$; $5 \%$ ) was found. The cardiac output before and nine hours after TIPS, calculated by two dimensional echocardiography $(7.9$ (1.7) $v 9.1$ (2.2) $1 / \mathrm{min}$ ), was comparable with the corre- sponding invasively determined values (8.5 (1.7) $v 10.0$ (1.7) $1 / \mathrm{min}$ ) (fig 1).

Table 2 summarises the haemodynamic data obtained with the Swan-Ganz catheter before and after TIPS. TIPS implantation induced a significant sharp rise in heart rate (change 9.5 (10.1) beats/min; 13\%), systolic blood pressure (16.8 (23.1) $\mathrm{mm} \mathrm{Hg;} \mathrm{15 \% ),} \mathrm{and} \mathrm{right} \mathrm{atrial}$ pressure (5.9 (2.6) $\mathrm{mm} \mathrm{Hg} ; 101 \%$ ), whereas the diastolic blood pressure did not change significantly. Systolic (change $15.3(5.5) \mathrm{mm} \mathrm{Hg}$; $81 \%$ ), diastolic (9.7 (4.8) $\mathrm{mm} \mathrm{Hg} ; 107 \%)$, and mean (12.8 (5.3) mm Hg; 92\%) pulmonary artery pressures, as well as pulmonary capillary wedge pressure $(10.5$ (4.0) $\mathrm{mm} \mathrm{Hg} ; 111 \%$ ), cardiac output (3.7 (1.6) $1 / \mathrm{min} ; 47 \%$ ), stroke volume $(30.5(14.5) \mathrm{ml} ; 28 \%)$, and total pulmonary resistance (48.3 (43.7) dyn $\cdot \mathrm{s} \cdot \mathrm{cm}^{-5}$; $34 \%)$ increased significantly. Systemic vascular resistance decreased significantly (change 226 (171) dyn $\cdot \mathrm{s} \cdot \mathrm{cm}^{-5} ; 27 \%$ ).

In the subgroup of nine patients for whom the period of catheter measurements was extended to nine hours, immediate haemodynamic changes comparable with the main study group were observed after the TIPS procedure. During the nine hour follow up period, the pulmonary artery pressures, the right atrial pressure, and the cardiac output returned towards the preshunt values, but remained significantly elevated (change at nine hours: mean pulmonary artery pressure, $4.0(2.4) \mathrm{mm} \mathrm{Hg}$, $27 \%$; pulmonary capillary wedge pressure, 2.6 (3.1) $\mathrm{mm} \mathrm{Hg}, 27 \%$; right atrial pressure, 2.5 (2.5) $\mathrm{mm} \mathrm{Hg}, 39 \%$; cardiac output, 1.4 (1.3) $1 / \mathrm{min}, 16 \%)$. The systemic vascular resistance remained significantly reduced (change at nine hours: 219 (129.8) dyn $\cdot \mathrm{s} \cdot \mathrm{cm}^{-5}, 27 \%$ ), whereas the total pulmonary resistance did not differ significantly from preshunt values (table 2 , fig $1)$.

Table 3 compares the haemodynamic variables in the splanchnic and systemic circulations of the subgroup of nine patients before and nine hours after the TIPS procedure. The shunt resulted in a significant reduction in portoatrial pressure gradient (change 8.8 (2.7) $\mathrm{mm} \mathrm{Hg} ; 43 \%)$ and the portohepatic vascular resistance (1370 (357) dyn $\left.\cdot \mathrm{s} \cdot \mathrm{cm}^{-5} ; 72 \%\right)$. Portal vein blood flow increased significantly (1.4 (0.53) $1 / \mathrm{min}$; 127\%).

Table 2 Haemodynamics before and within nine hours of insertion of a transjugular intrahepatic portosystemic stent shunt (TIPS) in patients with portal hypertension

\begin{tabular}{|c|c|c|c|c|c|c|c|c|c|}
\hline \multirow[b]{2}{*}{ Variables measured } & \multirow{2}{*}{$\begin{array}{l}\text { Normal } \\
\text { range }\end{array}$} & \multicolumn{2}{|l|}{ Before TIPS } & \multicolumn{2}{|c|}{5 min after TIPS } & \multirow[b]{2}{*}{$90 \min n=9$} & \multirow[b]{2}{*}{$3 h n=9$} & \multirow[b]{2}{*}{$6 h n=9$} & \multirow[b]{2}{*}{$9 h n=9$} \\
\hline & & $n=17$ & $n=9$ & $n=17$ & $n=9$ & & & & \\
\hline HR (beats/min) & $70(8)$ & $74.2(17.8)$ & $78.3(21.1)$ & $83.7(13.6)^{\star \star}$ & $87.1(19.8)^{\star}$ & $81.8(22.6)$ & $81.6(12.4)$ & $85.7(13.5)$ & $86.3(15.1)$ \\
\hline $\mathrm{BP}$, syst (mm Hg) & $131(13)$ & $114(21.4)$ & $119(22.3)$ & $131(20.6)^{\star}$ & $126(26.1)$ & $114(19.3)$ & $115(15.4)$ & $116(17.9)$ & $114(19.6)$ \\
\hline $\mathrm{BP}$, diast $(\mathrm{mm} \mathrm{Hg})$ & $82(7)$ & $71.7(10.6)$ & $74.4(10.4)$ & $73.9(7.2)$ & $74.4(7.7)$ & $69.4(11.8)$ & $68.3(13.2)$ & $67.2(14.1)$ & $65.6(17.2)$ \\
\hline $\mathrm{P}_{\mathrm{PA}}$, syst $(\mathrm{mm} \mathrm{Hg})$ & $21.5(3.9)$ & $19.1(6.5)$ & $20.9(6.9)$ & $34.5(8.7)^{\star \star}$ & $34.0(10.3)^{\star \star}$ & $26.1(7.1)^{\star \star}$ & $26.2(6.2)^{\star \star}$ & $26.2(5.9)^{\star}$ & $25.9(5.6)^{\star}$ \\
\hline $\mathrm{P}_{\mathrm{P}}$, diast $(\mathrm{mm} \mathrm{Hg})$ & $8.8(1.8)$ & $8.9(4.0)$ & $10.0(5.1)$ & $18.5(5.6)^{\star \star}$ & $18.4(6.9)^{\star \star}$ & $13.6(3.8)^{\star}$ & $13.9(2.9)^{\star}$ & $14.4(3.0)^{\star}$ & $14(4.2)^{\star}$ \\
\hline $\mathrm{P}_{\mathrm{PA}}(\mathrm{mm} \mathrm{Hg})$ & $14.4(2.7)$ & $13.8(5.3)$ & $15.1(6.3)$ & $26.5(7.2)^{\star \star}$ & $25.8(8.7)^{\star \star}$ & $19.4(5.0)^{\star}$ & $19.0(5.0)^{\star}$ & $19.3(4.5)^{\star}$ & $19.2(4.9)^{\star}$ \\
\hline $\mathrm{P}_{\mathrm{PC}}(\mathrm{mm} \mathrm{Hg})$ & $8.3(2.9)$ & $9.4(3.8)$ & $9.7(4.8)$ & $19.8(5.6)^{\star \star}$ & $18.7(6.9)^{\star \star}$ & $13.6(3.2)^{\star}$ & $12.6(2.5)^{\star}$ & $12.7(2.9)^{\star}$ & $12.2(2.9)$ \\
\hline $\mathrm{P}_{\mathrm{RA}}(\mathrm{mm} \mathrm{Hg})$ & $4.2(1.3)$ & $5.8(2.7)$ & $6.3(3.0)$ & $11.6(3.6)^{\star \star}$ & $12.2(4.3)^{\star \star}$ & $8.9(3.7)^{\star}$ & $8.4(3.1)^{\star}$ & $9.2(3.5)^{\star}$ & $8.7(2.9)^{\star}$ \\
\hline $\mathrm{CO}(1 / \mathrm{min})$ & $6.3(2.4)$ & $8.1(1.6)$ & $8.5(1.7)$ & $11.9(2.4)^{\star \star}$ & $12.4(2.1)^{\star \star}$ & $9.6(1.8)^{\star}$ & $10.0(1.7)^{\star}$ & $10.2(1.7)^{\star}$ & $10.0(1.7)^{\star}$ \\
\hline $\mathrm{SV}(\mathrm{ml})$ & $89(30)$ & $113(27.2)$ & $114(33.5)$ & $143(31.8)^{\star \star}$ & $147(37.4)^{\star \star}$ & $125(35.8)^{\star}$ & $127(36.9)^{\star \star}$ & $123(30.8)^{\star}$ & $119(29.4)$ \\
\hline SVR $\left(\right.$ dyn $\left.\cdot \mathrm{s} \cdot \mathrm{cm}^{-5}\right)$ & $1170(270)$ & $824(242)$ & $820(228)$ & $600(265)^{\star \star}$ & $538(184)^{\star \star}$ & $645(151)^{\star \star}$ & $623(161)^{\star \star}$ & $592(129)^{\star \star}$ & $601(164)^{\star \star}$ \\
\hline TPR $\left(\right.$ dyn $\left.\cdot s \cdot \mathrm{cm}^{-5}\right)$ & $158(48)$ & $140(58.5)$ & $140(39.8)$ & $188(69.5)^{\star}$ & $167(44.3)$ & $163(37.1)$ & $153(34.2)$ & $153(32.4)$ & $157(39.2)$ \\
\hline
\end{tabular}

Values are expressed as mean (SD). ${ }^{\star} \mathrm{p}<0.05,{ }^{\star \star}{ }^{\star} \mathrm{p}<0.01 v$ before TIPS.

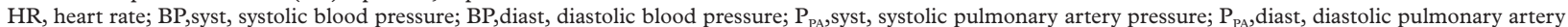
pressure; $\mathrm{P}_{\mathrm{PA}}$, mean pulmonary artery pressure; $\mathrm{P}_{\mathrm{PC}}$, pulmonary capillary wedge pressure; $\mathrm{P}_{\mathrm{RA}}$, right atrial pressure; $\mathrm{CO}$, thermodilution measured cardiac output; $\mathrm{SV}$, stroke volume calculated by thermodilution; SVR, systemic vascular resistance; TPR, total pulmonary resistance. 
Table 3 Haemodynamics in the splanchnic and systemic circulation before and nine hours after insertion of a transjugular intrahepatic portosystemic stent shunt (TIPS) in a subgroup of nine patients with portal hypertension

\begin{tabular}{llll}
\hline Variables measured & Before TIPS & $\begin{array}{l}\text { Nine hours } \\
\text { after TIPS }\end{array}$ & Change \\
\hline Portoatrial pressure gradient $(\mathrm{mm} \mathrm{Hg})$ & $20.4(4.0)$ & $11.7(3.2)^{\star}$ & $8.8(2.7)$ \\
Portal vein blood flow velocity $(\mathrm{cm} / \mathrm{s})$ & $20.8(6.5)$ & $47.5(10.6)^{\star}$ & $26.9(4.5)$ \\
Portal vein blood flow $(1 / \mathrm{min})$ & $1.1(0.51)$ & $2.5(0.64)^{\star}$ & $1.4(0.53)$ \\
Portohepatic vascular resistance $\left(\mathrm{dyn} \cdot \mathrm{s} \cdot \mathrm{cm}^{-5}\right)$ & $1887(540)$ & $525(175)^{\star}$ & $1370(357)$ \\
\hline
\end{tabular}

Values are expressed as mean (SD). ${ }^{\star} \mathrm{p}<0.01 v$ before TIPS.

Portal vein blood flow was calculated from the portal vein blood flow velocity and the portal vein diameter (mean $(\mathrm{SD}) 1.46(0.24) \mathrm{cm})$.

\section{Discussion}

The baseline echocardiographic data suggest an alteration in the diastolic, but not the systolic, left ventricular function in the patients with alcoholic cirrhosis. These findings are supported by another echocardiographic study ${ }^{18}$ of cirrhotic patients, mainly chronic alcoholics, with an elevated left ventricular end diastolic volume index, whereas the left ventricular end systolic volume index was almost unchanged compared with healthly adults. In contrast, Askansis $e t a l^{19}$ showed increased end diastolic and end systolic left ventricular volumes in chronic alcoholics, indicating an additional systolic dysfunction. Estruch et a ${ }^{20}$ observed increased left ventricular end diastolic diameters in active alcoholics, but not in nonalcoholic cirrhotic patients. Dancy et $a l^{21}$ found that the increased left ventricular dimensions observed in alcoholics were directly related to alcohol, but were independent of the presence and severity of liver disease.

Liver cirrhosis is characterised by a hyperdynamic circulation, with an increased cardiac preload $^{22}$ and a decreased cardiac afterload. ${ }^{23}$ For healthy hearts, the diastolic filling of the left ventricle and the systolic emptying would be enhanced under these haemodynamic conditions. However, in rats with cirrhosis, a limited cardiac preload reserve was shown. ${ }^{22}$ Our echocardiographic findings and the additional catheter data support the existence of a similar haemodynamic situation in our patients with alcoholic cirrhosis. The increased right atrial pressures up to nine hours after the intervention indicate that the acute blood volume shift from the splanchnic to the systemic circulation induced by the TIPS procedure exceeds the filling capacity of the right ventricle. The persistent increase in the pulmonary capillary wedge pressure and the significantly increased left atrial diameter nine hours after the intervention indicates a diminished left ventricular preload reserve, which triggers secondary effects on the pulmonary circulation. These are reflected in a persistent moderate increase in the pulmonary artery pressures and the total pulmonary resistance. However, the fact that right atrial pressure, pulmonary artery pressures, pulmonary capillary wedge pressure, and total pulmonary resistance returned towards the baseline value during the nine hour follow up period indicates extensive cardiac compensation by rapid distribution and excretion of the shunted blood volume.

Another factor that may influence the haemodynamic effects of the TIPS procedure is the impairment of $\beta$-adrenergic receptor function in cirrhotic cardiomyopathy. ${ }^{6}{ }^{24}$ It has been well recognised that blood noradrenaline levels are elevated in cirrhotic patients ${ }^{25}{ }^{26}$ and that baseline noradrenaline levels correlate positively with the severity of the cirrhosis. ${ }^{3}$ Elevation of the sympathetic tone may be responsible for the decreased $\beta_{2}$-adrenergic density in circulating lymphocytes of cirrhotic patients ${ }^{27}$ and in cardiomyocyte plasma membranes in the cirrhotic rat model. ${ }^{28} 29$ These findings are assumed to play a causal role in the inadequacy of the heart rate increase to compensate for the increased cardiac preload found after the creation of a TIPS.

It has been hypothesised that a portosystemic shunt may diminish the hepatic clearance of gut derived vasoactive agents ${ }^{30}$ - for example, endotoxin ${ }^{31}$ - which contribute to the activation of nitric oxide synthase of endothelial and smooth muscle cells. ${ }^{32-34}$ In addition, a further increase in the concentration of glucagon and other mediators, such as prostaglandins and vasointestinal polypeptides, may contribute to a shunt induced diffuse vasodilatation. $^{35} 36$ These vasoactive agents have been reported to be additional relevant factors influencing the pulmonary and systemic circulations after creation of a portosystemic shunt. However, the differential effects of the shunt-induced blood volume shift on the pulmonary and systemic circulations argues against a predominant role for these humoral factors in the haemodynamic changes after TIPS in our study. One would expect that these vasoactive substances, once eliminated by hepatic clearance, would affect the systemic and pulmonary vascular beds in the same way.

In our patients, the increase in portal vein blood flow (1.4 1/min; table 3 ) nine hours after the TIPS implantation was associated with a comparable increase in cardiac output (1.5 $1 / \mathrm{min}$; table 2 ). These haemodynamic changes were associated with a substantial reduction in the portohepatic vascular resistance $(72 \%$; table 3) and the systemic vascular resistance (27\%; table 2). Thus one major explanation for the persistent decrease in systemic vascular resistance after TIPS implantation is assumed to be the haemodynamic effects of the shunt itself. Our data suggest that the fall in portohepatic vascular resistance after the creation of a portosystemic stent shunt in portal hypertension is mainly responsible for the further decrease in the systemic vascular resistance. This effect on systemic vascular resistance, which has been confirmed in other studies, ${ }^{37} 38$ may be of great clinical importance because of its possible negative effects on renal function.

In contrast with these effects on the systemic circulation, there are somewhat conflicting results on the effects of TIPS on the pulmonary circulation. In our study, the total pulmonary resistance significantly and sharply increased and remained moderately elevated nine hours after the TIPS procedure. Van der Linden et $a l^{37}$ reported an acute increase in pulmonary vascular resistance immediately after opening of the shunt and a delayed decrease towards the preshunt values within 30 days of the shunt procedure in patients with alcoholic $(n=13)$ 
and non-alcoholic ( $\mathrm{n}=3$ ) cirrhosis, including six cases with ascites. However, Colombato et $a b^{\beta 8}$ observed a decrease in pulmonary vascular resistance immediately after the shunt procedure in patients with alcoholic $(n=10)$ and non-alcoholic $(n=5)$ cirrhosis, including seven cases with ascites. The inconsistency of the findings in the various studies might be explained by differing underlying cardiac and circulatory states in the cirrhotic patients, dependent on the cause and severity of the liver disease. Whereas diastolic function of the left ventricle has an effect on total pulmonary resistance, systemic vascular resistance is more dependent on the systolic left ventricular function. Therefore, a pre-existing clinically not apparent diastolic dysfunction in a hyperdynamic left ventricle, as in our patients with alcoholic cirrhosis, may explain the opposite reactions of total pulmonary resistance and systemic vascular resistance immediately after TIPS.

In summary, our results indicate that, in our patients with alcoholic cirrhosis, the acute blood volume shift from the splanchnic to the systemic circulation after the TIPS procedure was sufficient to unmask a diastolic dysfunction of the already hyperdynamic left ventricle. In addition, it must be taken into consideration that the TIPS procedure was associated with a further reduction in the already decreased systemic vascular resistance found in portal hypertension. However, all of these acute haemodynamic changes were, to a great extent, compensated for within nine hours of the intervention, and were not of major clinical relevance in our study population.

Altogether, the findings suggests a coexisting clinically not apparent diastolic myocardial dysfunction in our patients with alcoholic cirrhosis, which, at a later stage may be complicated by a concomitant impairment of myocardial contractility, leading to so called "alcoholic cardiomyopathy". ${ }^{21}$ In this situation, the TIPS procedure could be complicated by high output congestive heart failure as described in a case study. ${ }^{13}$ Future studies investigating haemodynamic effects of TIPS procedures in portal hypertension should rigorously define the inclusion criteria for patients in order to categorise the haemodynamic effects of TIPS according to the cause of the cirrhosis (non-alcoholic $v$ alcoholic) and severity of the disease.

\section{STUDY LIMITATIONS}

The identification of a specific alcoholic cardiomyopathy in our patients with alcoholic cirrhosis based on the echocardiographic data determined in this study is not possible. Firstly, because of the hyperdynamic circulation from the start in patients with cirrhosis, the left ventricular ejection fraction appears to be an unreliable variable to use to quantify preclinical impairment of the left ventricular systolic function in patients with alcoholic cirrhosis. Our findings suggest that future echocardiographic investigations should be directed more toward assessing diastolic myocardial function and particularly toward detecting impaired left ventricular diastolic filling in the early stages of the disease in cirrhotic patients. Secondly, we were not able to clearly discriminate between cirrhotic cardiomyopathy per se and presumed alcoholic cardiomyopathy in our patients, because supplementary echocardiographic data for patients with non-alcoholic cirrhosis were not obtained in this study. Therefore additional echocardiographic investigations are necessary to define very strict criteria with regard to this issue. Finally, our study design did not allow the exclusion of possible influences of endogenous vasoactive agents on the haemodynamic changes observed after the TIPS procedure.

The authors would like to thank Mrs Bärbel Spielberger for technical assistance with catheter measurements, and Dr Jaqueline Kramer-Maier and Mrs Beth Padden for help with the English translation.

1 Murray JG, Dawson AM, Sherlock S. Circulatory changes in chronic liver disease. Am $\mathcal{F}$ Med 1958;24:358-67.

2 Gould L, Shariff M, Zahir M, et al. Cardiac hemodynamics in alcoholic patients with chronic liver disease and a presystolic gallop. $\mathcal{F}$ Clin Invest 1969;48:860-8.

3 Grose RD, Nolan J, Dillon JF, et al. Exercise-induced left ventricular dysfunction in alcoholic and non-alcoholic cirrhosis. F Hepatol 1995;26:326-32.

4 Kelbaek H, Erikson J, Brynjolf I, et al. Cardiac performance in patients with asymptomatic alcoholic cirrhosis of the liver. Am f Cardiol 1984;54:852-5.

5 Darsee JR, Heymsfield SB, Miklozek CL. Cirrhotic cardiomyopathy: the hyperdynamic-unloaded-failing heart.
Circulation 1979;60(suppl II):38.

$6 \mathrm{Ma}$ Z, Lee SS. Cirrhotic cardiomyopathy: getting to the heart of the matter. Hepatology 1996;24:451-9.

7 Rössle M, Haag K, Ochs A, et al. The transjugular intrahepatic portosystemic stent-shunt procedure for variceal bleeding. N Engl f Med 1994;330:165-71.

8 LaBerge JM, Ring EJ, Gordon RL, et al. Creation of transjugular intrahepatic portosystemic shunts with wallstent endoprosthesis: results in 100 patients. Radiology 1993; 187:413-20.

9 Bredgard Sorensen M, Bille-Brahe NE, Christiansen L, et al. Hemodynamics in patients undergoing porto-caval shunt operations. Acta Anaesthesiol Scand 1982;26:425-8.

10 Levy J, Zeppa R, Hudson DG, et al. Early hemodynamic effects of the distal splenoreal shunt. Surg Forum 1976;25: 370-1.

11 Hadengue A, Moreau R, Sogni P, et al. Risk of adverse hemodynamic effects after intrahepatic shunts (TIPS): preliminary results. [abstract] Hepatology 1992;62:244A.

12 Helton WS, Belshaw A, Althaus S, et al. Critical appraisal of the angiographic portocaval shunt. Am F Surg 1993;5:56671 .

13 Braverman AC, Steiner MA, Picus D, et al. High-output congestive heart failure following transjugular intrahepatic portal-systemic shunting. Chest 1995;107:1467-9.

14 Friedman HS, Cirillo N, Schiano F, et al. Vasodilatory state of decompensated cirrhosis: relation to hepatic dysfunction, ascites, and vasoactive substances. Alcohol Clin Exp Res 1995;19:123-9.

15 Ruiz-del-Arbol L, Monescillo A, Jiminez W, et al. Paracentesis-induced circulatory dysfunction: mechanism and effect on hepatic hemodynamics in cirrhosis. Gastroenterology 1997;113:579-86.

16 Schiller NB. Two-dimensional echocardiographic determination of ventricular volume, systolic function and mass. Circulation 1991;84:I280-7.

17 Lentner C. Heart and circulation. In: Geigy scientific tables. Basel: Ciba-Geigy Ltd, 1990;5:41-182.

18 Keller H, Bezjak V, Stegaru B, et al. Ventricular function in Keller H, Bezjak V, Stegaru B, et al. Ventricular function in
cirrhosis and portosystemic shunt: a two-dimensional cirrhosis and portosystemic shunt: a two-dimens

19 Askanas A, Udoshi M, Sadjadi SA. The heart in chronic alcoholism: a non-invasive study. Am Heart f 1980;99:916.

20 Estruch R, Fernandez-Sola J, Sacanella E, et al. Relationship between alcoholic cardiomyopathy and liver disease in chronic alcoholism. Hepatology 1995;22:532-8.

21 Dancy M, Bland JM, Leech G, et al. Preclinical left ventricular abnormalities in alcoholics are independent of nutritional status, cirrhosis and cigarette smoking. Lancet 1985;1:1122-5.

22 Inglés AC, Hernández I, Garciá-Estan J, et al. Limited cardiac preload in conscious cirrhotic rats. Am f Physiol 1991; 260:H1912-17.

23 Bosch J, Pizcueta MP, Fernandez M, et al. Hepatic, splanchnic and systemic hemodynamic abnormalities in portal

24 Gerbes AL, Remien J, Jungst D, et al. Evidence for downregulation of $\beta 2$-adrenoceptors in cirrhotic patients with regulation of $\beta 2$-adrenoceptors in cir
severe ascites. Lancet 1986;1:1409-10.

25 Ring-Larsen H, Hesse B, Henrisken JH, et al. Sympathetic nervous activity and renal and systemic hemodynamics in 
cirrhosis: plasma norepinephrine concentration, hepatic extraction, and renal release. Hepatology 1982;2:304-10.

26 Bichet DG, Van Putten VJ, Schrier RW. Potential role of increased sympathetic activity in impaired sodium and
water excretion in cirrhosis. N Engl f Med 1982;307:1552water

27 Bernardi M, Rubboli A, Trevisani F, et al. Reduced cardiovascular responsiveness to exercise-induced sympathoadrenergic stimulation in patients with cirrhosis. Hepatology 1991;12:207-16.

$28 \mathrm{Ma} Z$, Miyamoto A, Lee SS. Role of altered $\beta$-adrenoceptor signal transduction in the pathogenesis of cirrhotic cardiomyopathy in rats. Gastroenterology 1996;110:1191-8

29 Lee SS, Marty J, Mantz J, et al. Desensitization of myocardial $\beta$-adrenergic receptors in cirrhotic rats. Hepatology 1990;12:481-5.

30 Abelmann WH. Hyperdynamic circulation in cirrhosis: a historical perspective. Hepatology 1994;20:1356-8.

31 Lumsden AB, Henderson JM, Kutner HM. Endotoxin levels measured by a chromogenic assay in portal, hepatic and peripheral blood in patients with cirrhosis. Hepatology 1988;8:232-6.
32 Guarner C, Soriano G, Tomas A. Increased serum nitrite and nitrate levels in patients with cirrhosis: relationship to and nitrate levels in patients with cirrhosis:

33 Vallance P, Moncada S. Hyperdynamic circulation in cirrhosis: a role for nitric oxide? Lancet 1991;337:776-8.

34 Moncada S, Higgs A. The L-arginine-nitric oxide pathway. N Engl F Med 1993;27:2002-12.

35 Benoit JM, Zimmermann B, Premen AJ. Role of glucagon in planchnic hyperemia of chronic portal hypertension. $A m \mathcal{F}$ Physiol 1987;251:G674.

36 Pizcueta MP, Casamitjana R, Bosch J. Decreased systemic vascular sensitivity to norepinephrine in portal hyperten-
sive rats: role of hyperglucagonism. Am F Physiol 1990;258: G191.

37 Van der Linden P, Le Moine O, Ghysels M, et al. Pulmonary hypertension after transjugular intrahepatic portosystemic shunt: effect on right ventricular function. Hepatology 1996;23:982-7.

38 Colombato LA, Spahr L, Martinet JP, et al. Hemodynamic adaptation two months after transjugular intrahepatic poradaptation two months after transjugular intrahepatic por-
tosystemic shunt (TIPS) in cirrhotic patients. Gut 1996;39: 600-4. 